\title{
Combined Application of Electrical Resistivity and GPR Techniques for Water Seepage Detection at New Cairo City, Egypt
}

\author{
Shokry A. Soliman ${ }^{1}$, Hossam M. El-Sayed ${ }^{2}$, T.F. Shazley ${ }^{1}$ and Abdellatif Younis ${ }^{3}$
}

${ }^{1}$ Egyptian Petroleum Research Institute, Cairo, Egypt.

${ }^{2}$ National Institute of Oceanography and Fisheries, NIOF, Egypt.

${ }^{3}$ National Research Institute of Astronomy and Geophysics, 11722 Helwan, Cairo, Egypt.

Received: 20 Sept. 2020 / Accepted 20 Nov. 2020 / Publication date: 30 Nov. 2020

\begin{abstract}
New Cairo City represents the eastern extension of the Greater Cairo, Egypt. In the study site, fracturing of the new residential buildings has been observed, in addition to the appearance of water seepage on the ground surface, which form some swamps. Geophysical surveys were carried out through two stages; electrical resistivity survey and GPR measurements. The interpretation results reveal the occurrence of four subsurface geoelectrical layers. The upper most two layers consist mainly of sands and clayey sands characterized by relatively low electrical resistivity values, with thickness reaching collectively to $4.3 \mathrm{~m}$. These layers are saturated by water and lying above a thick clay layer, which acts as a barrier, preventing the water infiltration to percolate into the deeper layers and leads to the formation of swamps on the ground surface. GPR profiles were performed above the drinking, sewage and irrigation pipes. GPR results confirm the presence of a water-saturated layer; especially around the pipelines. Water leakage from the sewage and irrigation pipes was proved to be the main source of seepage water in the area, which is trapped above the impermeable clay layer, forming the observed swamps. Further, the clay minerals are more sensitive to the swelling process, which may cause cracks and fractures for buildings.
\end{abstract}

Keywords: GPR;VES; seepage water; environmental and engineering problems; Cairo-Suez district

\section{Introduction}

Geophysical methods play a major role in studying the engineering and environmental problems safely, especially in the residential areas. Among these methods, the electrical resistivity method and ground penetrating radar (GPR) are the most widely used techniques and can be used effectively in the shallow subsurface investigation (Mohamaden, 2005; Abd El-Gawad, et al. 2018; El-Sayed and Mohamaden, 2018 and Araffa et al. 2019), geotechnical investigation (Carisand Van Asch, 1991; Pellerin, 2002; Adewuyi and Philips, 2018; Gemail, et al. 2020; and Alaminiokuma and Chaanda 2020) and exploration of water seepage around artificial buildings (Sharafeldin, et al. 2017; Prudhomme, et al. 2019; Salako, et al. 2019; and Abd El-Gawad, 2020). These geophysical methods can reveal precise information about the shallow subsurface layers, lateral and vertical variations in the surface soil characteristics and water saturation of the subsurface layers (Shaaban, et al., 2013).

The present work was conducted, in order to investigate the environmental and engineering problems, that were observed in the study site at the New Cairo City, $2 \mathrm{~km}$ southeast of the CairoSuez desert road and at $38 \mathrm{~km}$ east of Cairo City (Fig. 1a \& b). This area is one of the new established cities and represents an eastward extension of the Greater Cairo City. The study area consists of a group of residential buildings, surrounded by green parts and numerous gardens. Recently, the study area is suffering from a considerable amount of water seepage in the near surface section, which in turn initiated some swamps, to manifest the low topography areas, causing environmental pollution (Fig. 2). Also, engineering problems such as fracturing and tilting were detected in some buildings as a result of this water seepage. The problem addressed acts as a danger for the buildings foundation and needs scientific investigation and proper management plan. This work is a preliminary study to give a general idea about the conditions of the shallow subsurface layers, through applying some geophysical methods, such as electrical resistivity and GPR methods. Besides, some samples of surface water were collected for chemical analysis, to find out their source.

Corresponding Author: Shokry A. Soliman, Egyptian Petroleum Research Institute, Cairo, Egypt. Email: shokry61@yahoo.com 

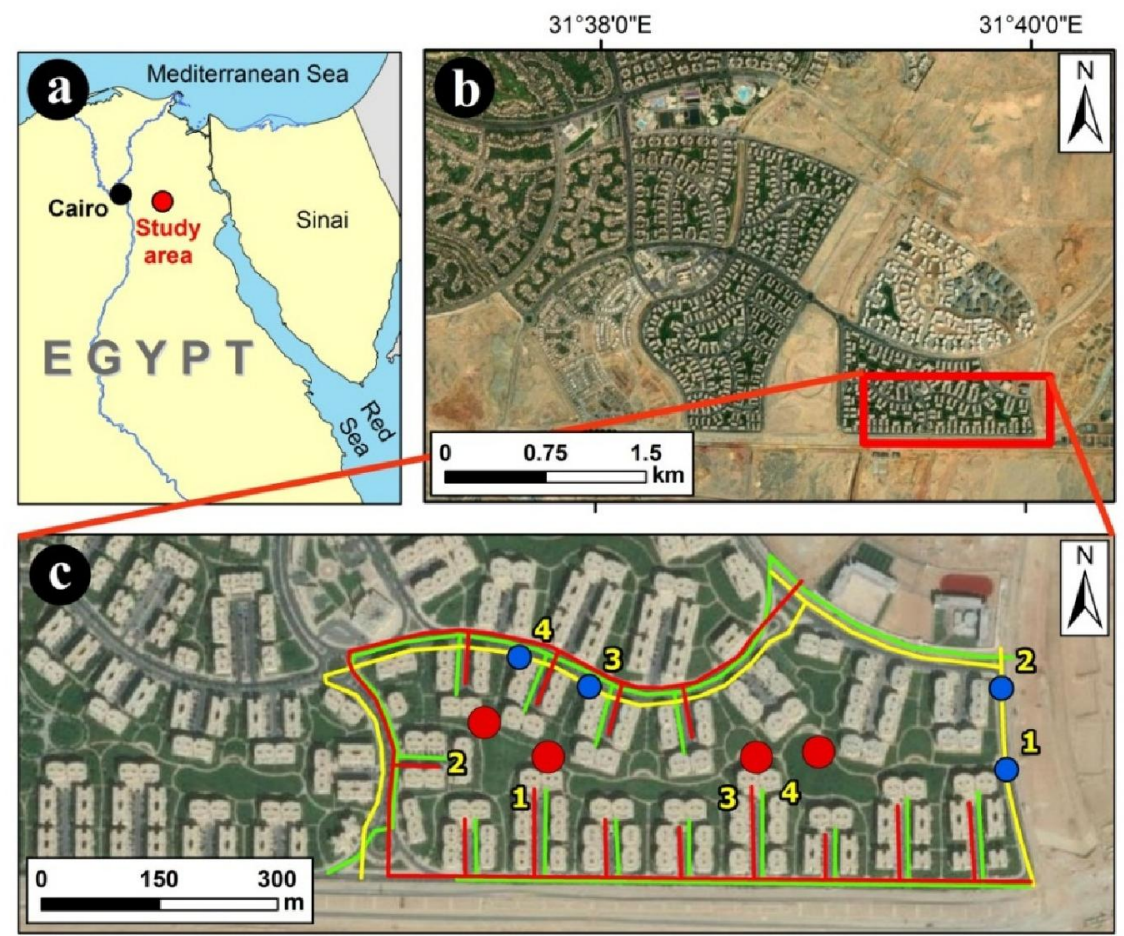

VES locations

- Water samples

GPR line over sewage pipe

GPR line over irrigation pipe

GPR line over water pipe

Fig. 1: (a) General Key map of the study area; (b) the study area and its portions; (c) VES's locations, GPR profiles and water samples

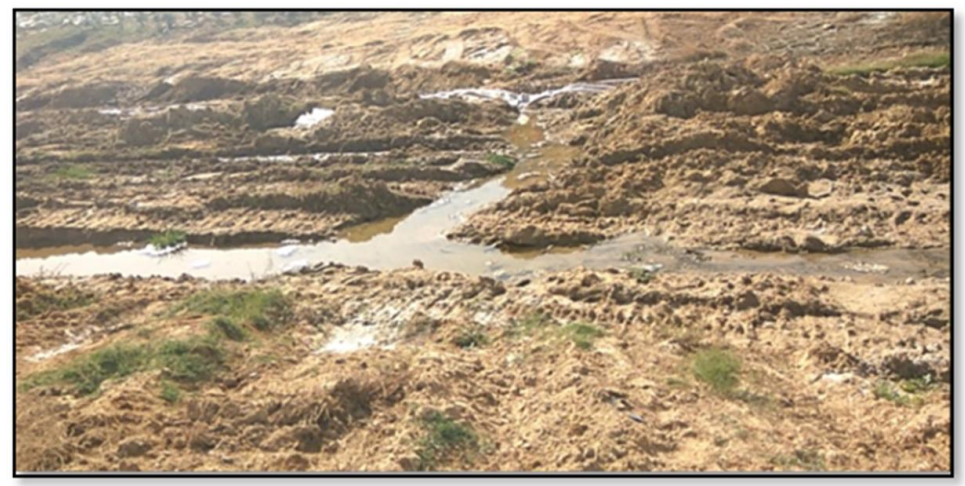

Fig. 2: The uprising seepage water forming swamps area.

The main objectives of this study are: (1) to identify the lateral and vertical thickness variations of the shallow subsurface layers, (2) to investigate the probable water leakage from water lines, irrigation pipes and/or sewer pipes, that may not be evident, and (3) to find out the water source in the area to find appropriate solutions. These goals are achieved, through the use of two complementary electrical resistivity and GPR methods.

The ground-penetrating radar (GPR) technology, known as georadar, is one of the latest surface geophysical survey techniques that have evolved over the past three decades, for shallow and highly accurate exploration (Annan, et al., 1991). This technique relies on the transmission of electromagnetic pulses through the GPR antenna (transmitter and receiver), with a specific frequency. GPR is a sturdy tool in geological, environmental, engineering, and archaeological applications, as 
well as the detection of the locations of water leakage (Stampolidis, et al., 2003; and Bimpas et al. 2010).GPR technique is used, in the present study, to identify parts, where water saturation increases, due to the influencing role of water in increasing the electrical conductivity and then affecting the spread of radar electromagnetic waves in the various soil components.

\section{Geology of the Area}

Generally, the study area is described by a gentle slope towards the northwest and low relief topography, and its elevation ranges from 241 to $245 \mathrm{~m}$ above sea level. The study area is characterized by hills and valleys, which are covered by loose sand, with small rounded flint pebbles, calcareous boulders and gravels (Fig. 3). These sediments belong to the Miocene age. The area of study is a part of the Cairo-Suez district and belongs to Greater Cairo City. Sedimentary rocks, exposed in the Greater Cairo area, belong to the Eocene to Quaternary (El Shazly, et al. 1980), while Said (1990) maintained that, the area lies in the Eastern Nile Delta province and is mainly occupied by rocks referred to Tertiary and Quaternary periods and sediments with mid-Tertiary basaltic flows. The main fault system, which controlling the Greater Cairo area is the NW-SE trend (Swedan,1991).

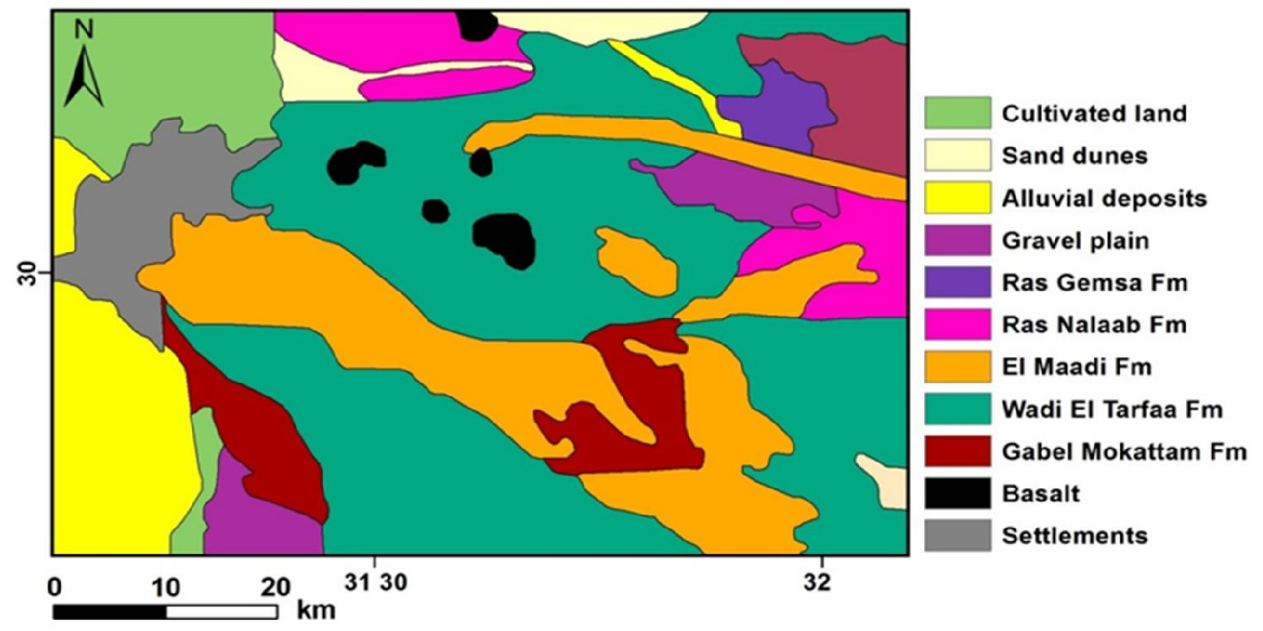

Fig.3: Geologic map of the Greater Cairo area (modified after El Shazly et al. and 1980; Williams andSmall 1984).

\section{Materials and Methods}

\section{Field Work}

In a preliminary field visit to the study area, water seepage and numerous swamps have been observed on the ground surface. This seepage is more dominant in low topography area at the northwestern part of the area. Many engineering problems, such as fracturing of some buildings are obvious; especially in the southeastern part. Based on the field visit, it was deduced that, there is a water-saturated layer very close to the earth's surface and lying above an impermeable layer acting as a barrier that prevents water infiltration to the deeper layers. To validate this hypothesis, electrical resistivity and GPR survey were recommended, to determine the shallow subsurface layers and to detect the vertical and lateral extensions of the expected water saturated layer. On the other hand, four water samples were collected (Fig. 1c) for chemical analysis, to define the source of this water.

\section{Data Acquisition and Inversion}

\subsection{Vertical Electrical Sounding}

The first stage includes measurements of four vertical electrical soundings (VES's), to delineate the lateral and vertical changes in the subsurface lithology, as well as to interpret the seepage in the low topography area (Fig. 1c). The electrical resistivity data were collected by using the Syscal-R2 instrument with $\mathrm{AB} / 2$ ranging from 1 to 200 m.IX1D v.3 software was used to determine the 
subsurface layers parameters (resistivity and thickness). The output models were used to construct a geoelectrical cross-section connecting VES's No. 2, 1, 3and 4, respectively.

\subsection{Ground Penetrating Radar}

GPR tool is useful in different pavement materials, like asphalt, concrete pavements and block pavements in most populated towns (Metwaly, 2015; Tosti et al. , 2018). The second stage includes measurements of GPR data, to identify the main sources of water seepage from the infrastructure of the study area. The GPR survey was carried out by the MALA RAMAC GPR System, with a Rough Terrain Antenna (RTA) system of a central frequency of $500 \mathrm{MHz}$, to reach the depth of about $4 \mathrm{~m}$. Another antenna of $250 \mathrm{MHz}$ frequency was used in the surveying over sewage pipes which are located at depths of about 6 to $7 \mathrm{~m}$ in the western part of the GPR surveyed area (Fig. 1c). The data processing was conducted, using the Reflex software ver. 8 (Sandmeier, 2012), several processing steps were applied to each radar profile separately, such as zero-time shift, background removal, band-pass filters (1- and 2-dimensional), median filter and automatic-gain control. Band-pass filtering was applied to eliminate high-frequency components. The GPR signal velocity was estimated based on the hyperbolic velocity matching from the response of the underground voids that it was $0.12 \mathrm{~m}$ /nsec. (Araffa, et al. 2019).

\section{Results}

\section{Electrical Resistivity Interpretation}

The geoelectrical cross-section (Fig. 4) indicates that, the shallow subsurface sequence of the study area consists of four geoelectric units; interpreted as; the superficial layer consists of surface alluvial deposits of sand, sandy clay to clay, with low electrical resistivity ranging between 7.7 and $10.5 \mathrm{Ohm} . \mathrm{m}$ and thickness reaching $0.85 \mathrm{~m}$. The second geoelectrical layer consists of clayey sand with moderate electrical resistivity values ranging from 13 to $31 \mathrm{Ohm} . \mathrm{m}$. The variation of electrical resistivity in this layer may be attributed to the percentage of sand. Its thickness ranges between 1.9 and $3.4 \mathrm{~m}$. The third geoelectrical layer consists of clay, with significant low electrical resistivity values (3.7 - 5.1 Ohm.m.) and has a thickness ranging between 15.1 and $24.5 \mathrm{~m}$, and overlaying the fourth geoelectrical layer, that consists of calcareous sandstone intercalated with clay which is characterized by moderate electrical resistivity values $(14.5-16.5 \mathrm{Ohm} . \mathrm{m})$.

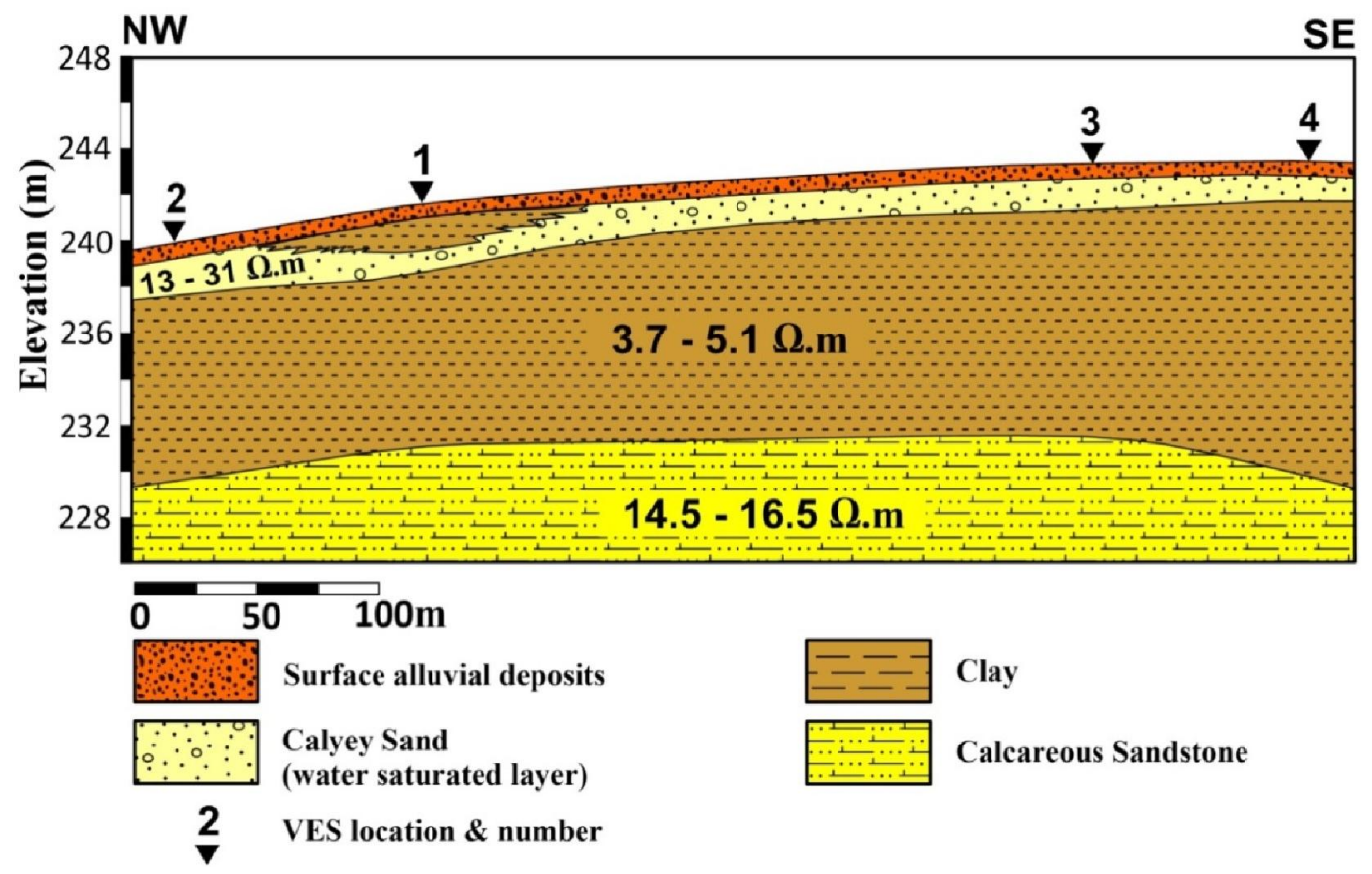

Fig. 4: Geoelectrical cross-section comprising VES's $2,1,3 \& 4$, respectively 


\section{GPR Data Interpretation}

The conductivity of materials affects the attenuation of the electromagnetic waves. Clays, silts and seepage water represent the materials that have high attenuation of the electromagnetic waves, while the materials that have low attenuation waves, such as dry sand, distilled water, and air. The interpretation of GPR profiles refers that there are four stratigraphic units as shown in fig (5).

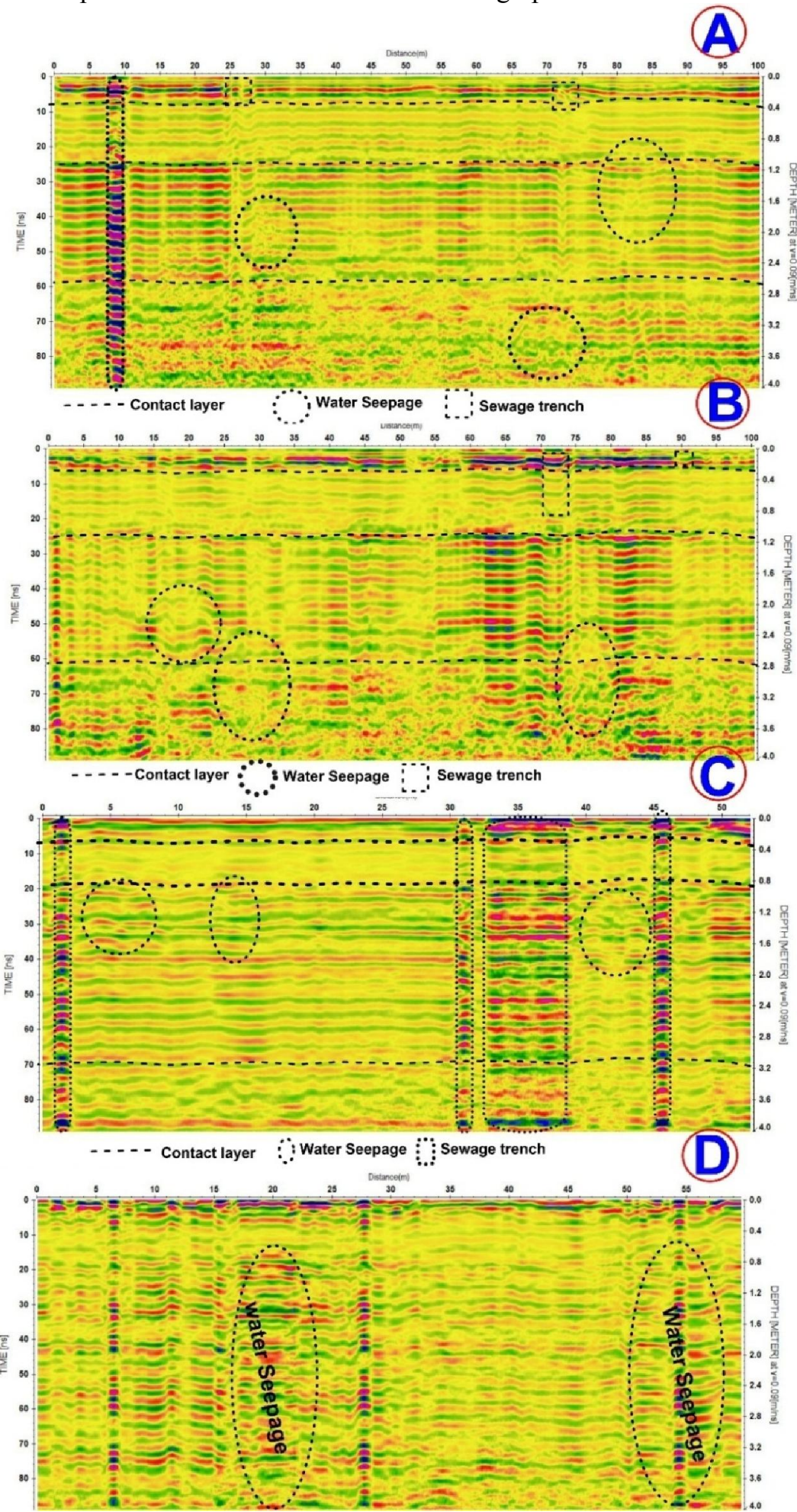

Fig. 5: 2D A GPR section shows the saturated soil with water along with profiles (A)1, (B)3, (C) 5 and (D) 8 . 
Also, the area of study is characterized by the presence of seepage of water results from the sewage and other utilities in the study area. According to conductivity, the qualitative GPR data interpretation reveals that, over the drinking water pipes, there is an evidence of four places in the southern border of the area (main pipes) and one in the northwestern part (sub-pipes) indicating the saturation of the soil with water at a depth ranging between 0.8 and $2.2 \mathrm{~m}$ (Fig. 5A.). It is worth mentioning that, the presence of seepage water at this shallow depth may indicate that, the source is not the water pipes, but a dispersion of surface water (mostly from the irrigation of gardens). The results of checking the sewage pipes exhibit that, the evidence of presence of soil saturated with water on the tracks of the sewage pipes, at a depth ranging from 2 to $4 \mathrm{~m}$ and concentrated only at the southern and southeastern parts of the area (Fig. 5B).

As for the western side of the area, where the depth of the pipes reaches about $7 \mathrm{~m}$, there is no evidence of any leakage on this side. To the north of the area, there is some evidence of sub-tracks inside the parking places, at a depth varying between 2 and $2.5 \mathrm{~m}$. While, there are many confirming evidences of waterlogged soil on the tracks of the irrigation pipeline at a depth ranging from 2 to $3 \mathrm{~m}$, which are mainly concentrated at the eastern and the northern borders of the area (Fig. 5D).

\section{Discussion}

From the field observations in the study area, there is seepage water in the low topography area causing damages to some buildings.GPR and electrical resistivity surveys in the study area provided valuable information that contributes to the explanation of the engineering problem and seepage water observed at the site. The obtained results of the VISE's data reveal that, the subsurface sequence consists of four geoelectric layers where the most upper two layers are mainly of alluvial deposits saturated with water. These layers consist mainly of sand and clayey sand, and are characterized by relatively low resistivity values. The thickness of this water-saturated zone reaches $4.3 \mathrm{~m}$. These layers are followed by a clay layer, with a thickness ranging between 15.1 and $24.5 \mathrm{~m}$. The impermeable character of this clay layer makes it a good barrier and prevents the infiltration of the leaked water to the deeper layers, which explains the considerable amount of water seepage along the surface and the observed swamps across the study area.

The GPR results show an evidence for the presence of water-saturated soil on the tracks of the sewage pipes, at a depth ranging from 2.5 to $4.3 \mathrm{~m}$, as concentrated only at the southern and southeastern parts of the GPR surveyed area. No evidence of water seepage at the western side of the area, where the depth of the pipes reaches about $7 \mathrm{~m}$. Many confirmed waterlogged soil is present on the tracks of the irrigation pipelines at a depth ranging from 2.5 to $3.3 \mathrm{~m}$, and are mainly concentrated at the eastern and the northern boundaries of the GPR survey area. The results of the leakage examination from the drinking water pipes, exhibit that, there is an evidence at four places in the southern border of the area (Fig. 6) and one at the northwestern part indicating the saturation of the soil with water at a depth ranged between 0.8 and $2.2 \mathrm{~m}$, which is highly concordant with the electrical resistivity survey results.

Additionally, the results of the chemical analysis of the four collected water samples (Table 1) show a significant increase in the total dissolved solids and ammonia concentration of the water samples collected from the eastern border of the area which confirms the leakage of sewage pipes at the southeastern part (APHA, 1992). These results confirmed the detected seepage from sewage pipes at the southern and southeastern parts.

Table 1:Chemical characteristics of the water samples

\begin{tabular}{cccccc}
\hline \multirow{2}{*}{ Sample No. } & TDS & \multicolumn{2}{c}{ Ammonia } & \multicolumn{2}{c}{ Nitrate } \\
\cline { 2 - 6 } & $\mathbf{m g} / \mathbf{L}$ & $\mathbf{m g} / \mathbf{L}$ & $\mathbf{m e q} / \mathbf{L}$ & $\mathbf{m g} / \mathbf{L}$ & $\mathbf{m e q} / \mathbf{L}$ \\
\hline $\mathbf{1}$ & 3470 & 4.7 & 0.261 & 5.43 & 0.088 \\
$\mathbf{2}$ & 2950 & 0.02 & 0.001 & 28.8 & 0.465 \\
$\mathbf{3}$ & 1086 & 0.08 & 0.005 & 0.47 & 0.008 \\
$\mathbf{4}$ & 1222 & 3.67 & 0.203 & 14.53 & 0.234 \\
\hline
\end{tabular}




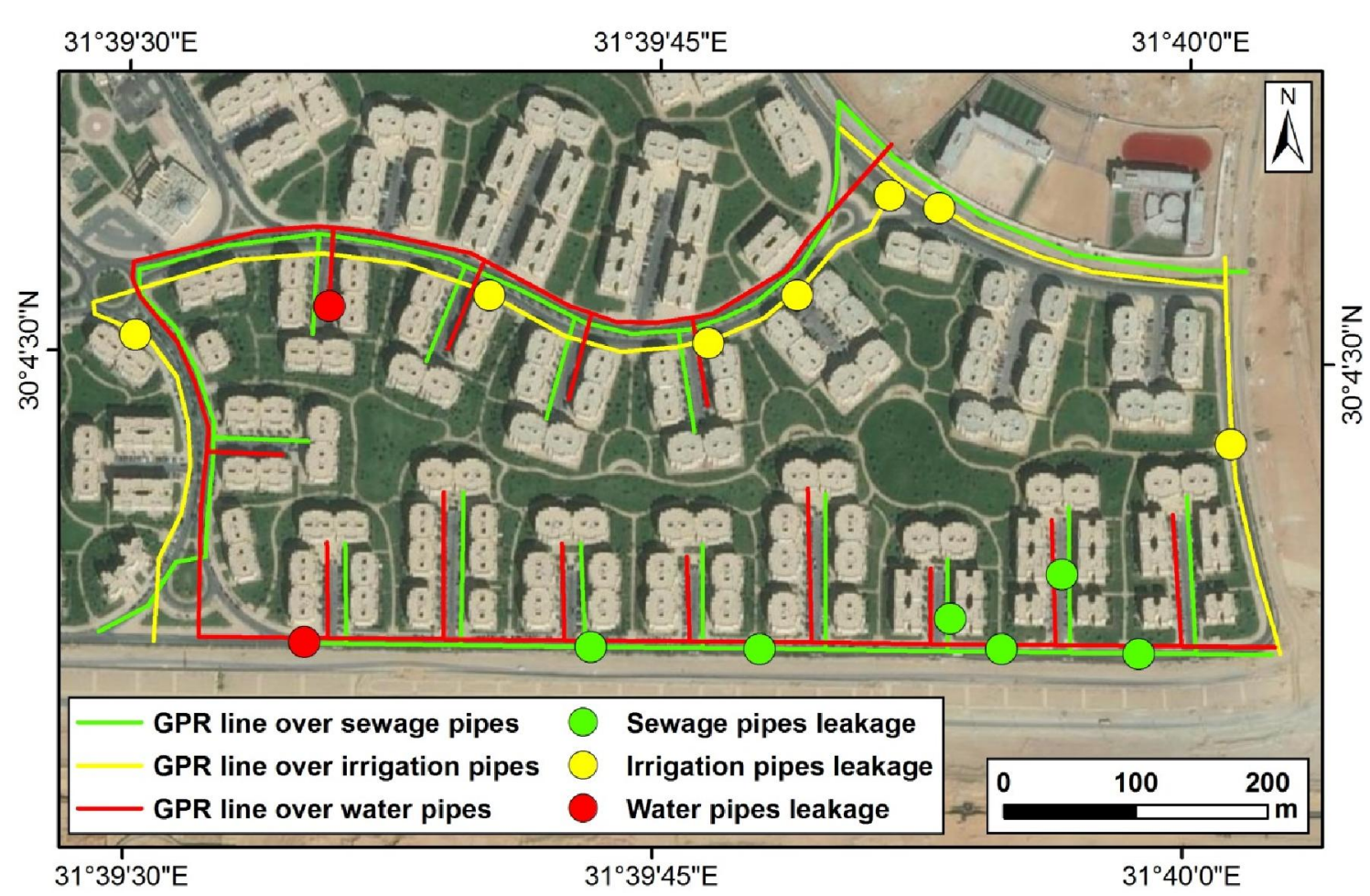

Fig. 6: Locations of the detected water leakage areas

Based on all these results, it is recommended to drill some boreholes that penetrate the impermeable clay layer. These boreholes will provide suitable pathways for the surface water to infiltrate to the deeper layers, which in turn eliminate the surface swamps and water seepage, in addition to the treatment of the detected water leakage from the pipes in the area.

\section{Conclusions}

The integration between electrical resistivity and GPR methods strongly contributed to the investigation of the observed water seepage problem in the New Cairo City. It provided valuable tools for interpreting the hypothesis assumed, based on the field visit and observations. The leakage of sewage pipes in addition to the excess surface irrigation plays a major role in recharging the subsurface layers with a considerable amount of water, which is unfortunately, cannot pass through the subsurface layers, due to the presence of the impermeable clay layer at shallow depths.

\section{Conflict of interest}

On behalf of all authors, the corresponding author states that there is no conflict of interest.

\section{References}

Abd El-Gawad, A. 2020. Water Seepage Source at the Extension of Tourah Clay Quarry, Southeastern Cairo Based on Geological and Geoelectrical Resistivity Measurements. Earth Sci., 9(3):108.

Abd El-Gawad, A.M.S., A.S. Helaly, and M.S.E. Abd El-Latif, 2018. Application of geoelectrical measurements for detecting the ground-water seepage in clay quarry at Helwan, southeastern Cairo, Egypt. Nriag J Astron. Geoph., 7(2):377-389.

Adewuyi, O.I., and O.F. Philips, 2018. Integrated Geophysical and Geotechnical Methods for PreFoundation Investigations. J. Geol Geophys.,7: 453.doi: 10.4172/2381-8719.1000453

Alaminiokuma, G.I., and M.S. Chaanda, 2020. Geophysical Investigation of Structural Failures Using Electrical Resistivity Tomography: A Case Study of Buildings in FUPRE, Nigeria. J Earth Sci Geotech Eng., 10(5):15-33. 
Annan, A.P., S.W. Cosway, and J.D. Redman, 1991. Water table detection with ground-penetrating radar. In: Soc. Explor. Geophys. (Annual International Meeting Program with Abstracts). 494497.

APHA., 1992. Standard methods for the examination of water and wastewater. $18^{\text {th }}$ ed. American Public Health Association, Washington, DC.

Araffa, S.A., M.I. Mohamadin, H. Sabet, and M.S. Takey 2019.Geophysical interpretation for groundwater exploration around Hurghada area, Egypt. NRIAG J. Astr Geophys., 8(1):171179.

Araffa, S.A., S.A. Soliman, A. El Khafif, A. Younis, and T.F. Shazley, 2019. Environmental investigation using geophysical data at East Sadat City, Egypt. Egyptian Journal of Petroleum 28: $117-125$.

Bimpas, M., A. Amditis, and N. Uzunoglu, 2010. Detection of water leaks in supply pipes using continuous wave sensor operating at 2.45GHz. J. App Geophys., 70:226-236.

Caris, J.P.T., and T.W. Van Asch, 1991. Geophysical, geotechnical and hydrological investigations of a small landslide in the French Alps. Eng Geol., 31(3-4):249-276.

El Shazly, E.M., M.A. El Ghawaby, A.B. Salman, S.M. Khawask, H. El Amin, M.M. El Rakaiby, I.E. El Aassy, A.A. Abd El Megid, and S.I. Mansour, 1980. Geological Map of Egypt. Remote Sensing Center, Academy of Scientific Research and Technology, Cairo, Egypt.

El-Sayed, H.M., and M.I.I. Mohamaden, 2018. Application of Resistivity Method for Groundwater Exploration in Barrani - Salum Sector, Northwestern Coast, Egypt. EGS J. 15(1):159-170

Gemail K.S., S. Shebl, M. Attwa, S.A. Soliman, A. Azab, and M.H. Farag 2020. Geotechnical assessment of fractured limestone bedrock using DC resistivity method: a case study at New Minia City, Egypt. Nriag J Astron Geophys., 9(1):272-279.

Metwaly, M. 2015. Application of GPR technique for subsurface utility mapping: a case study from urban area of Holy Mecca, Saudi Arabia. Measurement. 60: 139-145.

Mohamaden, M.I.I., 2005. Electric resistivity investigation at NuweibaHarbour Gulf of Aqaba, South Sinai, Egypt. Egy. J. Aq. Res., 31(1):58-67.

Pellerin, L., 2002.Applications of electrical and electromagnetic methods for environmental and geotechnical investigations. Surv Geophys., 23(2-3):101-132.

Prudhomme, K.D., M.A. Khalil, G.D. Shaw, M.A. Speece, K.R. Zodrow, and T.M. Malloy, 2019. Integrated geophysical methods to characterize urban subsidence in Butte, Montana, USA. J. App Geophys., 164:87-105.

Said, R., 1990.The Geology of Egypt. Amsterdam, El-Sevier Publications, Co.

Salako, A.O., A.G. Osotuyi, and A.A. Adepelumi, 2019. Seepage investigations of heterogeneous soils beneath some buildings using geophysical approaches: example from southwestern Nigeria. Int. J. Geo-Eng., 10(1):11.

Sandmeier, K.J., 2012. The 2D processing and 2D/3D interpretation software for GPR, reflection Seismic and refraction seismic. Software Catalogue 2012, Karlsruhe, Germany.

Shaaban, F., A. Ismail, U. Massoud, H. Mesbah, A. Lethy, and A.M. Abbas 2013. Geotechnical assessment of ground conditions around a tilted building in Cairo, Egypt using geophysical approaches. Ar J Geosci., 6(12):4961-4972.

Sharafeldin, M., K.S. Essa, N. Sayıl, M.A.S. Youssef, Z.E. Diab, and H. Karsl1 2017. Geophysical Investigation Of Ground Water Hazards In Giza Pyramids And Sphinx Using Electrical Resistivity Tomography And Ground Penetrating Radar: A Case Study. In 9th Congress of the Balkan Geophysical Society 2017(1):1-5. Euro AssocGeosci Eng.

Stampolidis, A., P. Soupios, F. Vallianatos, and G.N. Tsokas, 2003. Detection of leaks in Buried plastic water distribution pipes in urban places-a case study, in: Proceedings of the 2nd International Workshop on Advanced Ground Penetrating Radar:120-124.

Swedan, A.H.,1991. A note on the geology of Greater Cairo area Egyptian mineral resources authority. Ann Geol. Surv. Egy., 17:239-251.

Tosti, F., L.B. Ciampoli, F. D’Amico, A.M. Alani, and A. Benedetto, 2018. An experimental-based model for the assessment of the mechanical properties of road pavements using groundpenetrating radar. Const Build Mat. 165:966-974.

Williams, G.A., and J.O. Small 1984. A study of the Oligo-Miocene basalt in the Western Desert. In: Proc Petrol Explo Seminar, EGPC, Cairo: 252-268. 